\title{
Mejora de una estrategia didáctica para innovar el aprendizaje del idioma inglés
} Improving a teaching strategy to innovate the learning of the english language Melhorar a estratégia de ensino para inovar a aprendizagem da língua Inglês

\author{
NADIA KASSANDRA MAY ACOSTA \\ UNIVERSIDAD AUTÓNOMA DE CAMPECHE, México \\ nmayxx@hotmail.com
}

\author{
ROGER MANUEL PATRÓN CORTÉS \\ UNIVERSIDAD AUTÓNOMA DE CAMPECHE, México \\ Roger_patron_cortes@hotmail.com
}

\section{Resumen}

Las instituciones y organizaciones han tenido grandes cambios para lograr poco a poco la incorporación de tecnologías, ser más competitivos y desarrollarse eficientemente entre otras; esto representa todo un reto, sobre todo porque estos cambios avanzan constantemente por su misma naturaleza, sin embargo no todo avanza a la par de la tecnología, sobre todo en algunos ámbitos dentro de las instituciones educativas.

El entorno pide que los estudiantes estén mejor preparados debido a la alta competencia en el campo laboral, esto conlleva a una mejora mientras reciben educación, se les de las herramientas para mejorar sus habilidades tanto tecnológicas como cognitivas y sociales.

Desde temprana edad en el colegio, los estudiantes, van desarrollando habilidades, es función del área académica que se creen programas de unidad de aprendizaje y planes de clase enfocado en los puntos que se desea el alumno obtenga, que sea beneficioso para él a largo plazo, hasta que impacte su vida laboral. 
El presente trabajo gira en torno a la parte más íntima de una institución escolar y es, dentro del aula de clases, con el objetivo de mejorar una estrategia didáctica en el proceso de aprendizaje de un alumno de nivel medio superior, mediante el desarrollo de habilidades tecnológicas, actitudinales y cognoscitivas para aprender inglés como segundo idioma, de manera significativa.

Palabras clave: Instituciones, tecnología, desarrollo, educación.

\section{Abstract}

Institutions and organizations have done changes to gradually achieve the incorporation of technologies, become more competitive or to have more development; this represents a challenge, especially since these changes are constantly moving because of its nature, however not everything advances on a par with the technology, especially in some areas within educational institutions.

The environment demands that students are better prepared because of the high competition in getting a job, this leads to receive better education and to have better tools to improve technological, cognitive and social skills.

From an early age in school, students may be developing different skills, that why the academic area has an important role by creating programs learning units and lesson plans which are focused on the main points every student needs, thinking in giving the students a long term benefit until it impacts their working lives.

This work is based on the transformation of the most intimate part of an educational institution which is classroom, with the aim of improving a teaching strategy on the learning process of a student of high school level, by developing technological, social and cognitive skills, to learn English as a second language.

Key words: Institutions, technology, development, education. 


\section{Resumo}

Instituições e organizações têm sido grandes mudanças para alcançar gradualmente incorporando tecnologias tornam-se mais competitivo e desenvolver com eficiência, entre outros; isto representa um desafio, especialmente porque essas mudanças em constante movimento por sua própria natureza, no entanto nem todos os avanços a par com a tecnologia, especialmente em algumas áreas dentro das instituições educacionais.

O ambiente exige que os estudantes estão mais preparados por causa da alta competição no local de trabalho, isso leva a uma melhoria ao receber educação são as ferramentas para melhorar as habilidades tecnológicas e cognitivas e sociais.

Desde cedo na escola, os alunos estão desenvolvendo habilidades, é uma função dos programas acadêmicos da área de aprendizagem planos de unidade e de aula focando os pontos que deseja o aluno a obter, é benéfico para ele que pensar a longo prazo até que ela afeta sua vida profissional.

Este trabalho gira em torno da parte mais íntima de uma instituição educacional e está em sala de aula, com o objectivo de melhorar a estratégia de ensino no processo de aprendizagem de um estudante do ensino médio, pelo desenvolvimento de competências tecnológica, de atitude e cognitiva aprendizagem de Inglês como segunda língua de forma significativa.

Palavras-chave: Instituições, tecnologia, desenvolvimento, educação.

Fecha recepción: Enero $2016 \quad$ Fecha aceptación: Junio 2016

\section{Introducción}

Todo entorno en las instituciones puede ser mejorado, esto se logra a base de experiencia, feedback, observación, entre otras y enfocándose en las áreas que sean pertinentes; el aprendizaje organizacional es corregir aquello que se observe que no está funcionando. 
Las instituciones educativas son un poco más tradicionales y los estudiantes de hoy en día tienen diversos retos por vencer y las instituciones deben adoptar nuevas dinámicas para la guía de los alumnos en el ámbito tecnológico, lograr encontrar soluciones y sobre todo actuar para mejorar su desarrollo y competitividad en el campo laboral.

Uno de los actores dentro de las instituciones educativas es el docente, quien se percata de cerca de las necesidades de los estudiantes y puede dar sus puntos de vista para mejorar los programas de unidades de aprendizaje o los planes de clase, está involucrado directamente en la enseñanza.

Si bien la tecnología ha generado nuevas formas de hacer las cosas en muchos aspectos sociales y humanos, aún en el ámbito educativo hace falta un poco más la integración de algunas modernas herramientas, reestructurar la forma de enseñar y por ende de aprender.

El profesor, quien elabora planes de clase, da oportunidad de explorar sobre la práctica pedagógica y como dice el libro de Serie Pocket Mentor (2009) "puede incorporar hechos reales por medio de actividades y lograr perspectivas multidireccionales, lo cual forma parte de aprendizaje organizacional".

\section{OBJETIVO}

Mejorar el proceso de aprendizaje de un alumno de nivel medio superior, mediante el desarrollo de una estrategia didáctica enfocado en las habilidades tecnológicas, para aprender de manera significativa el uso del "Primer Condicional" (First Conditional) en inglés como un segundo idioma.

\section{PLANTEANDO LA SITUACIÓN}

Ser estudiantes hoy en día va más allá de ir a la escuela, cada día hay más competencia en el campo laboral y lo más recomendable es adaptar sus conocimientos a encontrar diversas soluciones.

El crear un plan para reforzar la Enseñanza/Aprendizaje del Primer Condicional los ayuda a verificar las estructuras, parte de la estrategia se basa en que éstos identifiquen, desarrollen y las utilicen, pero para que un aprendizaje no sea momentáneo y sí duradero, es necesario 
planearlos adecuadamente a su realidad y edad, además de agregar otros elementos que los ayude a desarrollar diferentes competencias, como son el desarrollo de herramientas tecnológicas, o desarrollar habilidades para trabajar en equipo o desarrollar competencias socio-emocionales le dará más oportunidad de ser competitivo.

La estrategia didáctica debe tener coherencia, ir de lo fácil a lo complejo; a continuación una guía para ejemplificar la secuencia didáctica, enfocada al área de inglés pero puede servir de base de cualquier tema y/o asignatura.

\section{DESARROLLO}

La presente estrategia está dirigida a estudiantes de la Escuela Preparatoria Dr. Nazario Víctor Montejo Godoy de la Universidad Autónoma de Campeche del nivel medio superior, entre 16 y 18 años de edad que se encuentran en el quinto semestre, primer bimestre en el cual es el desarrollo del tema del uso del Primer Condicional (First Conditional).

Centrada en el alumno para que adquiera el aprendizaje del Primer Condicional y fundamentada en tres competencias genéricas; la primera: se expresa y comunica; en los apartados de: Se comunica en una segunda lengua en situaciones cotidianas; y maneja las tecnologías de la información y la comunicación para obtener información y expresar ideas.

La segunda competencia genérica: aprende de forma autónoma; el apartado: aprende por iniciativa e interés propio a lo largo de la vida.

Tercera competencia genérica: Trabaja en forma colaborativa; asume una actitud constructiva, congruente con los conocimientos y habilidades con los que cuenta dentro de distintos equipos de trabajo.

Las competencias disciplinares a desarrollar son: Produce textos con base en el uso normativo de la lengua, considerando la intención y situación comunicativa; valora la relevancia del pensamiento y del lenguaje como herramientas para comunicarse en diversos contextos; desarrolla y aplica las habilidades de lectura, escritura, oralidad y escucha para comunicarse en una segunda lengua; utiliza las tecnologías de la información y 
comunicación para producir diversos materiales de estudio e incrementar sus posibilidades de formación.

Se hace hincapié que los puntos anteriores, son los estipulados en la Reforma Integral para la Educación Media Superior, tomándose en cuenta en especial, dentro de esta estrategia, la inclusión de herramientas tecnológicas para desarrollar la habilidad del estudiante, considerando que le dará mayor impulso y competitividad en un futuro, además de la adquisición del idioma.

A continuación se presentan las actividades para llevarla a cabo en tres diferentes momentos:

- AL INICIO, para guiar la entrada al tema.

- Haciendo uso del cañón dentro del salón de clases, se proyecta un sitio web, en donde se muestran las estructuras del tema. El alumno, además de anotar la página de internet, toma apuntes en su cuaderno, en donde se le pide identificar estructuras gramaticales.

- Se revisa el libro de texto: la gramática sobre el primer condicional se encuentra incluido en el libro, por lo que trabajarán en esa parte identificando las estructuras del First Conditional.

- Lluvia de ideas: se pedirá a los estudiantes que señalen los contenidos con Primer Condicional.

Este momento es diagnóstico y estas actividades de inicio se hacen para que los alumnos identifiquen el Primer Condicional, el papel del profesor es de guía para que el alumno sea participativo.

A continuación se presenta es una lista de cotejo en la Tabla 1, en donde el alumno hará una autoevaluación. 
Tabla 1

Lluvia de ideas

Criterios

Puntos

Utiliza libro para observar texto

5

Compara la estructura del primer condicional con oraciones en el texto

5

Utiliza cuaderno para anotar oraciones que considera están usando

5

primer condicional y por lo menos un consejo de los presentados en la

página web

Realiza la actividad con orden y limpieza

5

Total

20

Nota: Fuente de elaboración propia

- DESARROLLO, liga lo anterior y mantener al alumno motivado e interesado.

- Formar equipos de trabajo: de 5 personas

- Diálogos para simulación de un comercial: después de revisar las estructuras anteriores estructurarán diálogos

- En el cuaderno: redacta los diálogos trabajados y los incluirá en el cuaderno, este diálogo será leído por integrantes de otro equipo para su revisión

- Realizar la lectura del comercial: al haber terminado y revisado los diálogos en forma de comercial, dos miembros del equipo leerán su trabajo.

Momento formativo, en donde el papel del maestro es de coordinar y guiar, el alumno es el creador de modelos para su aprendizaje de manera activa.

Se hace una evaluación, empleando una rúbrica Tabla 2, en donde se señalan los criterios, se muestra el desarrollo de la habilidad socioemocional, el alumno hará una coevaluación, ya que al momento de leer y revisar el comercial de otro equipo seguirá aprendiendo las 
estructuras; también se realizará una heteroevaluación en el momento en que el profesor verifica los resultados de la coevaluación.

Tabla 2

Reporte escrito del desarrollo de un comercial

\begin{tabular}{|c|c|c|c|c|}
\hline Criterios & 3 & 2 & 1 & 0.5 \\
\hline $\begin{array}{l}\text { Participación } \\
\text { individual }\end{array}$ & $\begin{array}{l}\text { Utiliza su libro de } \\
\text { texto y cuaderno. } \\
\text { Participa } \\
\text { activamente. } \\
\text { Escribe el comercial }\end{array}$ & $\begin{array}{l}\text { Utiliza su libro de } \\
\text { texto y cuaderno. } \\
\text { Participa en más de } \\
\text { la mitad del ejercicio. } \\
\text { Escribe el comercial }\end{array}$ & $\begin{array}{l}\text { Visitó uno de los } \\
\text { sitios de internet. } \\
\text { Utiliza su libro de } \\
\text { texto y cuaderno. } \\
\text { No participa. } \\
\text { Escribe el comercial }\end{array}$ & $\begin{array}{l}\text { Utiliza su libro de } \\
\text { texto y cuaderno. }\end{array}$ \\
\hline Participación grupal & $\begin{array}{c}\text { Todos los integrantes } \\
\text { participan en la } \\
\text { actividad. } \\
\text { Analizan los textos } \\
\text { que les servirá de } \\
\text { guía. } \\
\text { Trabajan de manera } \\
\text { organizada. } \\
\text { Todos escuchan y } \\
\text { conviven de manera } \\
\text { respetuosa. } \\
\text { Alguien se ofrece } \\
\text { para leer el } \\
\text { comercial. }\end{array}$ & $\begin{array}{l}\text { La mayoría de los } \\
\text { integrantes participan } \\
\text { en la actividad. } \\
\text { Analizan los textos } \\
\text { que les servirá de } \\
\text { guía. } \\
\text { Trabajan de manera } \\
\text { organizada. } \\
\text { Todos escuchan y } \\
\text { conviven de manera } \\
\text { respetuosa. } \\
\text { Eligen a alguien para } \\
\text { leer el comercial. }\end{array}$ & $\begin{array}{c}\text { La mitad de los } \\
\text { integrantes participan } \\
\text { en la actividad. } \\
\text { Analizan los textos } \\
\text { que les servirá de } \\
\text { guía. } \\
\text { Trabajan de manera } \\
\text { desorganizada. } \\
\text { Escuchan y conviven } \\
\text { de manera } \\
\text { respetuosa. } \\
\text { Eligen a alguien para } \\
\text { leer el comercial. }\end{array}$ & $\begin{array}{c}\text { Menos de la mitad de } \\
\text { los integrantes } \\
\text { participan en la } \\
\text { actividad. } \\
\text { Analizan los textos } \\
\text { que les servirá de } \\
\text { guía. } \\
\text { Trabajan de manera } \\
\text { desorganizada. } \\
\text { Escuchan y conviven } \\
\text { de manera } \\
\text { respetuosa. } \\
\text { Nadie quiere leer el } \\
\text { comercial. }\end{array}$ \\
\hline $\begin{array}{l}\text { Desempeño cognitivo } \\
\text { en la elaboración del } \\
\text { comercial }\end{array}$ & $\begin{array}{l}\text { Presenta la } \\
\text { estructura del Primer } \\
\text { Condicional } \\
\text { correctamente. } \\
\text { Utiliza } 5 \text { oraciones } \\
\text { con }\end{array}$ & $\begin{array}{l}\text { Presenta la } \\
\text { estructura del Primer } \\
\text { condicional } \\
\text { correctamente. } \\
\text { Utilizan } 4 \text { oraciones } \\
\text { con } \quad \text { Primer }\end{array}$ & $\begin{array}{l}\text { Presenta la } \\
\text { estructura del Primer } \\
\text { condicional } \\
\text { correctamente. } \\
\text { Utilizan } 3 \text { oraciones } \\
\text { con } \quad \text { Primer }\end{array}$ & $\begin{array}{l}\text { Presenta la } \\
\text { estructura del Primer } \\
\text { condicional } \\
\text { correctamente. } \\
\text { Utilizan } 3 \text { oraciones } \\
\text { con } \quad \text { Primer }\end{array}$ \\
\hline
\end{tabular}




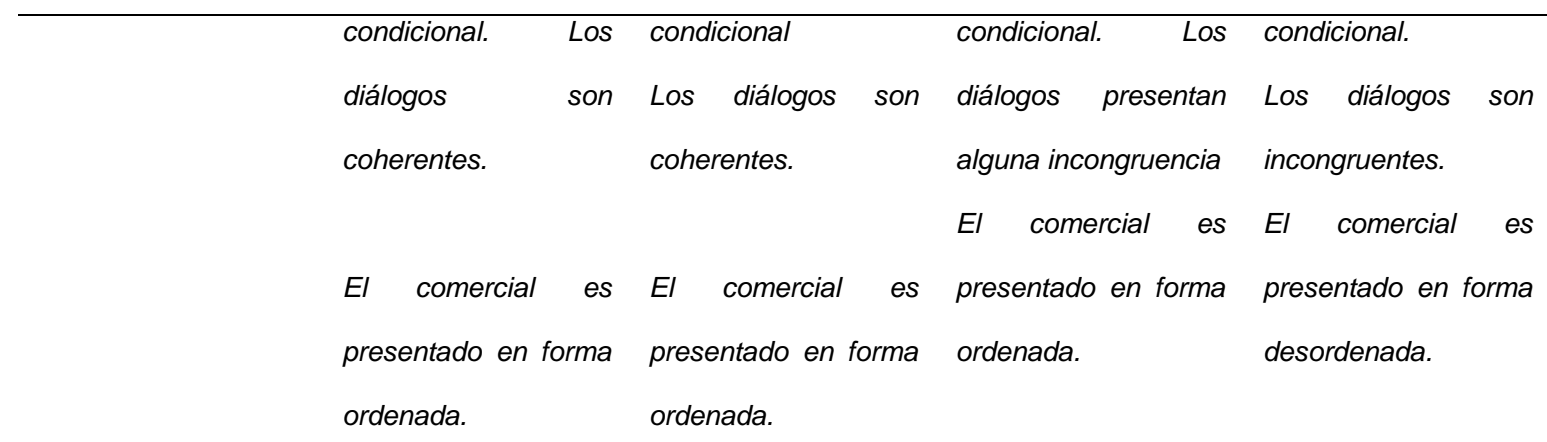

$\begin{array}{lllll}\text { Puntuación } & 9 & 6 & 3 & 1.5\end{array}$

Nota: Fuente de elaboración propia

- MOMENTO DE CIERRE, esta etapa es para asegurar el aprendizaje significativo, entre las actividades a realizar:

- Trabajar en equipos: continúa trabajando en sus grupos de 5 integrantes

- Realizar mapa conceptual: todos los integrantes de equipo contribuirán a la realización de un mapa conceptual en donde se incluyan las estructuras del Primer Condicional.

- Uso de cuaderno: de forma organizada anotan en su cuaderno el mapa conceptual elaborado en consenso.

- Uso de láminas: las cuales emplearán para plasmar el mapa conceptual para que se visualice apropiadamente.

- Descripción oral del mapa conceptual: dos alumnos del equipo de manera voluntaria explicarán el mapa conceptual elaborado.

Momento llamado sumativo, el papel del maestro es de guía y facilitador para el cumplimiento de las actividades y el papel del alumno es activo, participativo.

La evaluación de las actividades se hará mediante una rúbrica Tabla 3, en donde se aplicarán tanto la autoevaluación como la heteroevaluación, primero, los alumnos verificar si aprendieron las estructuras, en sus comentarios reflexionarán lo aprendido y por último el 
profesor verifica que las estructuras comprendidas en los mapas conceptuales sean los correctos gramaticalmente.

Tabla 3

Mapa conceptual

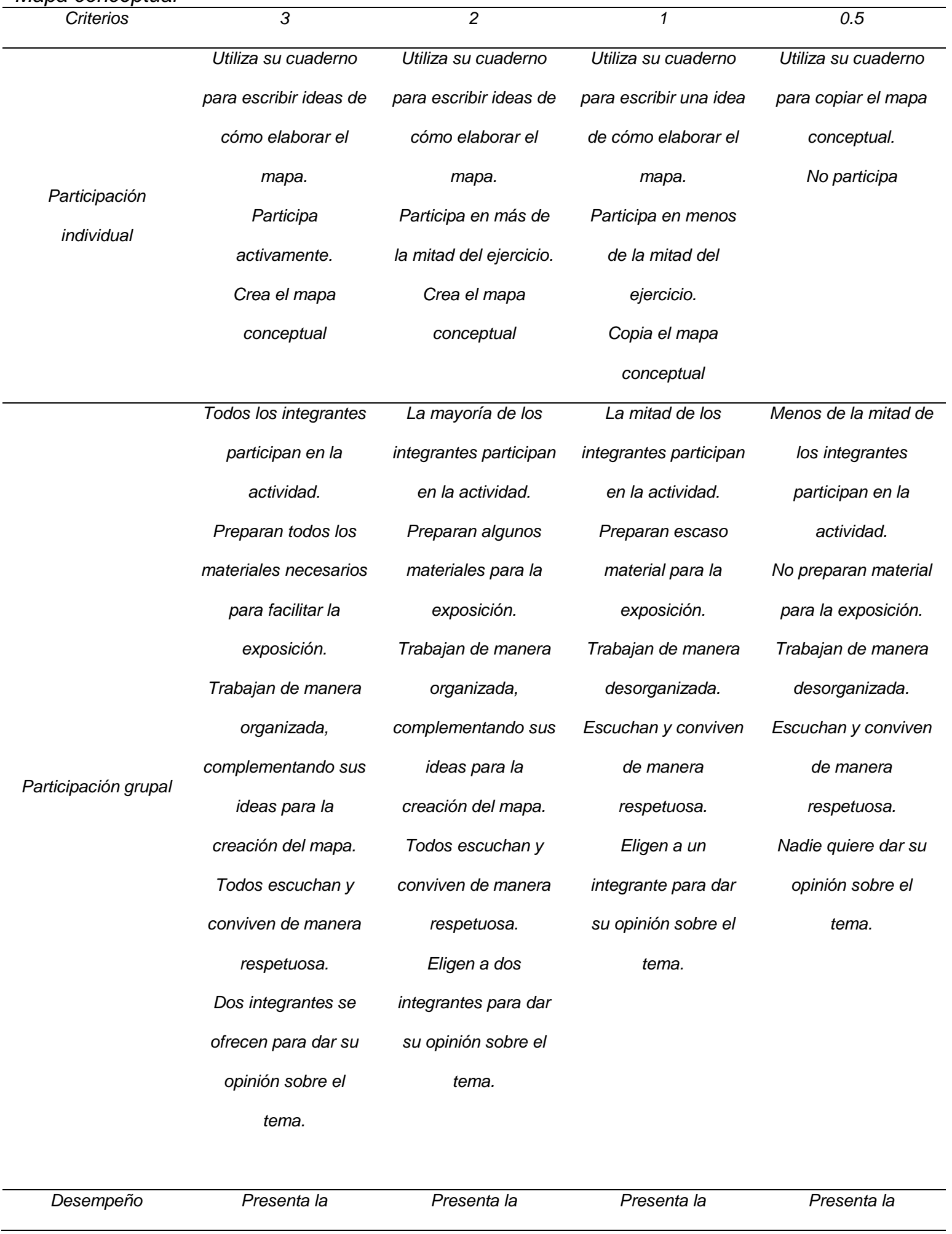




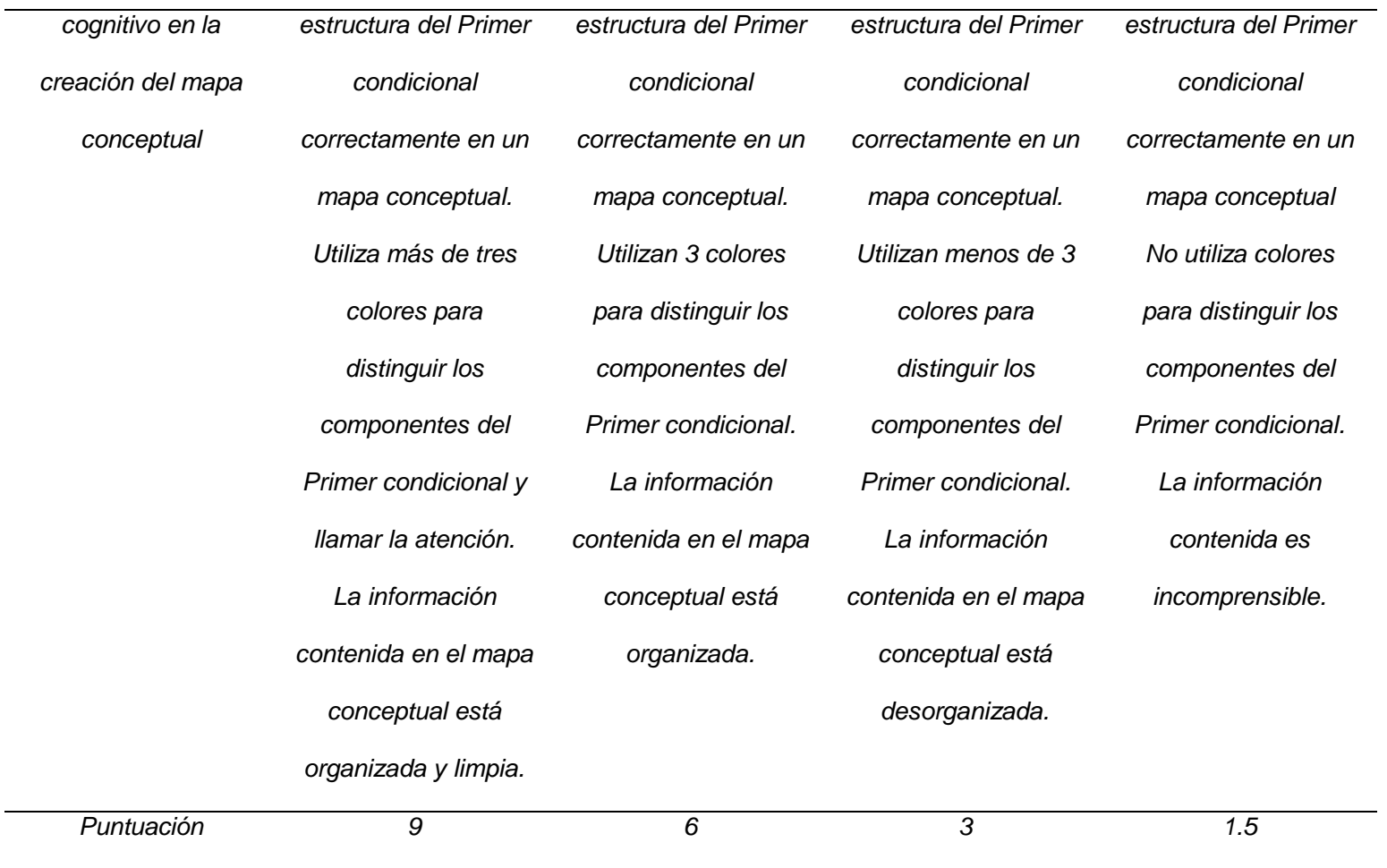

Nota: Fuente de elaboración propia

\section{EVALUACIÓN}

Uno de los puntos más álgidos es la evaluación, para planearla hay que tener especial cuidado, ya que persigue verificar que los procesos u objetivos sean logrados, hoy día es se debe realizar es evaluar por competencias y esta se define según Tobón, Rial, Carretero y García (2006): "Es el proceso mediante el cual se recopilan evidencias y se realiza un juicio o dictamen de esas evidencias teniendo en cuenta criterios preestablecidos para dar retroalimentación en aras de mejorar la idoneidad".

La evaluación busca obtener información de lo que nuestros estudiantes pueden hacer, para verificar si las expectativas del proceso y objetivos se cumplieron. Muestra hacia dónde dirigirse.

La evaluación busca tres diferentes momentos, descritos por Díaz y Hernández (2002), la diagnóstica para determinar las características del alumno antes del desarrollo del programa. El segundo momento es la evaluación formativa que tiene como objetivo informar los logros obtenidos, conocer las debilidades y fortalezas del proceso, permite retroalimentar y busca el mejoramiento del proceso enseñanza-aprendizaje. Por último la 
sumativa aquí se obtiene información del período de aprendizaje en la conclusión de un tema.

Por otra parte existen diferentes tipos de evaluación, la Autoevaluación, cuando el alumno evalúa sus propias actuaciones; coevaluación, es la utilizada en la evaluación de un trabajo y llevada a cabo por alumno-alumno o alumno-profesor y por último la Heteroevaluación, realizada por el profesor se evalúan actividades realizadas como pueden ser de actitud, limpieza, duración, entre otras.

Para que los alumnos adquieran competencias, es necesario clarificar cuales se potencializarán, y darles mayor énfasis al momento de evaluar las actividades, ser muy puntuales en cuanto a lo estipulado en las rúbricas.

Las competencias en las que se enfocan esta mejora de estrategia didáctica son:

- Desarrolla y aplica las habilidades de lectura y escritura para comunicarse en una segunda lengua

- Utiliza las tecnologías de la información y comunicación para producir diversos materiales de estudio

La evaluación deberá seguir su propósito, cabe mencionar que la heteroevaluación es en donde debe tenerse mayor cuidado, ya que algunas veces puede resultar complicado porque, Blázquez y otros (2007) mencionan que "Es un proceso importante dentro de la enseñanza, rico por los datos y posibilidades que ofrece y complejo por las dificultades que supone el enjuiciar las actuaciones de otras personas".

Parte de la evaluación en la estrategia didáctica consiste en plasmar el progreso en el nivel de desempeño de los estudiantes en la apropiación de las competencias, nos servirá de indicador para continuar con la estrategia o cambiar algunos aspectos, una evaluación sirve para retroalimentar varios aspectos.

La autoevaluación, bien guiada, formará parte trascendental de la vida del estudiante, es una herramientas clave en la adquisición del aprendizaje, puesto que podría darse cuenta de lo que les está funcionando y lo que no al momento de estudiar; estar conscientes de que 
todas las actividades que realicen es con el fin de tener un aprendizaje significativo e independiente.

La evaluación da la pauta de los objetivos alcanzados, es por ello que, el plan de evaluación para el progreso de la competencia va directamente relacionada con el tipo de competencia, es decir, habrá que dividirla en tres grandes áreas que son conocimiento, habilidad o actitud, además Ríos (2009) enfatizó que "la evaluación se orienta a derivar aprendizajes del desarrollo del currículum, sirviendo para mejorar el curso, para decidir qué materiales de instrucción y métodos son satisfactorios y cuándo es necesario cambiar”. Esto es la guía para diseñar una evidencia adecuada, el instrumento con el que se evaluará debe ser congruente, y adecuado a los momentos en los que se realizarán y la ponderación de los instrumentos debe formar parte de toda la planeación de la evaluación.

Los resultados de aprendizaje tienen relación con los indicadores de desempeño, los instrumentos de evaluación fueron elaborados para que exista congruencia uno con otro, así mismo los indicadores de desempeño guían al tipo de contenido de la competencia, en la estrategia didáctica se han tomado en cuenta: conocimiento, habilidad y actitud; a continuación se describen las especificaciones a los que se refiere:

- Distingue las formas de utilizar el primer condicional, el indicador de desempeño demuestra que el reporte contiene información pertinente al tema y la competencia que se pretende evaluar es de nivel conocimiento.

- Elabora escritura de un comercial, usando el primer condicional, guiándose de páginas de internet que les servirán de guía, el indicador de desempeño indica que el comercial es desarrollado con las estructuras del tema y se hace uso de la página de internet propuesta, la competencia a evaluar es de habilidades tecnológicas, haciendo uso adecuado de ella.

- Crea un mapa conceptual del primer condicional, de manera colaborativa y valora lo aprendido, el indicador de desempeño corrobora que la elaboración del mapa se realiza de común acuerdo y reporta lo aprendido, el nivel que se pretende evaluar es el cognoscitivo y actitudinal. 
Con anterioridad se les proporcionará a los alumnos los criterios con los que será evaluado Tabla 4, para que puedan apegarse a la guía, quedando de la siguiente manera:

- Inicio: en esta etapa la estrategia didáctica guiará la entrada al tema y motivará la participación de los alumnos por medio de la técnica de preguntas, terminando en una lluvia de ideas. Las actividades incluirán lectura del libro de texto con el tema de Primer Condicional, identificarán estructuras. Se desplegará en la pantalla una página de internet llamada "elblogdelinglés" el cual se puede consultar en http://elblogdelingles.blogspot.mx/2006/07/lesson-26-conditionals-i-probable.html, en donde se localizará la estructura presentada, y en el pizarrón estarán anotadas las estructuras junto con ejemplos de oraciones que se encuentran empleando el primer condicional, los alumnos deberán anotar de forma organizada en sus cuadernos lo que consideren pertinente; dentro del mismo blog, hay un apartado que habla sobre consejos que se les proporciona a personas que quieran aprender el idioma inglés, el consejo que cada alumno considere útil deberá ser anotado. Realizarán una autoevaluación, al reflexionar sobre los puntos importantes de la lluvia de ideas, esta primera parte los acerca al conocimiento conceptual pues es para iniciar el tema y en la lista de cotejo se autoevaluarán.

- Desarrollo: La estrategia didáctica se llama "simulación" al realizar la elaboración de un comercial, se dividirá el grupo en equipos de cinco personas, harán actividades basadas en el libro y se les encamina para utilizar primer condicional para elaborar un comercial, específicamente se abordará un tema de interés, el cual será la casa en la que vivió Frida Kahlo, harán uso de la tecnología para investigar sobre el tema, una vez concluida la investigación, la actividad incluye la lectura del comercial, como evidencia se pide a todos los integrantes anotar en su libreta el comercial, posteriormente se realiza la coevaluación, el comercial elaborado será revisado por otro equipo quienes evaluarán usando una lista de cotejo, finalmente la heteroevaluación que el profesor realice, verificando que los comerciales estén bien evaluados.

- Cierre: La estrategia didáctica consistirá en la creación de un mapa conceptual, la técnica será exponerlos ante el grupo y la actividad se realizará con la presentación de las estructuras del primer condicional, los integrantes de los equipos cambiarán 
para comprobar que las estructuras fueron aprendidas por ellos, sin importar que otro haya elaborado el mapa conceptual. Se visitará la página de Aula planeta para consultar la elaboración correcta de los mapas conceptuales en http://www.aulaplaneta.com/2014/05/21/recursos-tic/seis-herramientas-para-crearmapas-conceptuales/, expondrán y los comentarios finales se harán por parte del docente. El tipo de evaluación será autoevaluación ya que, antes de presentar sus mapas verificarán que las estructuras estén bien realizadas y con esto valorar lo aprendido.

Cuando se realiza una planeación tomando en cuenta los aspectos mencionados, se puede lograr la adquisición por competencias, de forma congruente, los instrumentos de evaluación, son básicos para referenciar hasta donde los alumnos adquieren las habilidades. Los profesores pueden confiar que los aspectos evaluados son relevantes para el aprendizaje. 
Tabla 4

Especificaciones de las Competencias

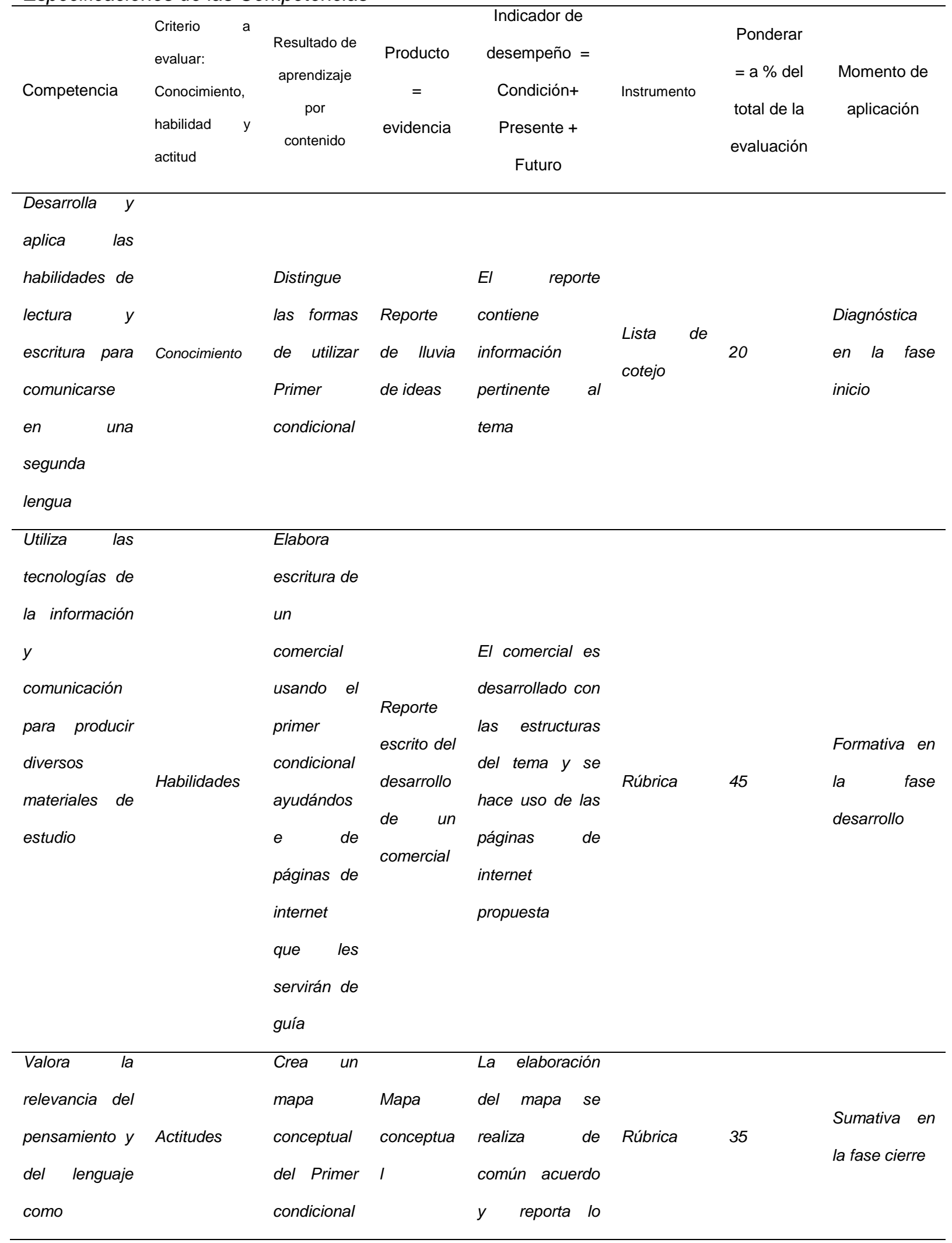




\begin{tabular}{|c|c|c|}
\hline herramientas & de manera & aprendido \\
\hline para & colaborati- & \\
\hline comunicarse & va y valora & \\
\hline en diversos & 10 & \\
\hline contextos & aprendido & \\
\hline
\end{tabular}

\section{CONCLUSIÓN}

El entorno exige cada vez más que los estudiantes estén mejor preparados debido a la alta competencia en el campo laboral, esto conlleva a un esfuerzo para mejorar en el ámbito educativo en donde alumnos/profesores tienen que poner mayor esfuerzo, en cuanto a aprender y enseñar tiene un significado más profundo. Así mismo, se requiere que, las herramientas para mejorar sus habilidades tanto tecnológicas, cognitivas y socioemocionales, sean exploradas y mejoradas.

Elaborar estrategias didácticas relevantes es el primer punto para ayudar al alumno en el proceso de aprendizaje, en este caso, se presenta la mejora de una estrategia de nivel medio superior, centrada en el estudiante, enfocada a la adquisición de conocimientos y uso de la estructura del tema "Primer Condicional" en inglés,como segundo idioma. Se prioriza el desarrollo de las habilidades antes mencionadas, haciendo el tema en cuestión, atractivo e involucrando al estudiante de manera activa en cada paso para lograr un aprendizaje significativo. 


\section{Bibliografía}

AulaPlaneta. (21 de mayo de 2014). Seis herramientas para crear mapas conceptuales. Obtenido de http://www.aulaplaneta.com/2014/05/21/recursos-tic/seisherramientas-para-crear-mapas-conceptuales/

Blázquez, A. C. (2007). Modelo para autoevaluar la práctica docente. Madrid, España: Wolters Kluwer España, S. A.

Díaz Barriga, F. y. (2002). ESTRATEGIAS DOCENTES PARA UN APRENDIZAJE SIGNIFICATIVO. D.F., México: McGRAW-Hill/INTERAMERICANA EDITORES, S. A. de C. V.

Mónica Tapia Stocker. (Diciembre de 2005). El Blog para aprender inglés. Obtenido de http://elblogdelingles.blogspot.mx/2006/07/lesson-26-conditionals-i-probable.html

Ríos, P. (2009). Evaluación en Tiempos de Cambio. Revista de Educación Digital y Nuevas Tecnologías, 32(5), 9-31.

Serie Pocket Mentor. (2009). CÓMO DAR FEEDBACK. Chile: HARVARD BUSINESS Press.

Tobón, S. R. (2006). Competencias, calidad y educación superior. Bogotá, Colombia: COOPERATIVA EDITORIAL MAGISTERIO. 